\title{
COMPORTAMENTO EMPREENDEDOR NO SETOR PÚBLICO: ANÁLISE COMPARADA DE DOIS PRESIDENTES DO BRASIL
}

DOI: 1014211/regepe.v5i2.338

Artigo recebido em: 07/12/2015

Artigo aprovado em: 21/05/2016

Isabella Monteiro Pereira - Universidade Federal de Lavras - UFLA ${ }^{1}$

Denis Renato de Oliveira - Universidade Federal de Lavras - UFLA ${ }^{2}$

Josiel Lopes Valadares - Universidade Federal de Viçosa - UFV ${ }^{3}$

Magnus Luiz Emmendoerfer - Universidade Federal de Viçosa - UFV ${ }^{4}$

Resumo: Propõe-se, neste trabalho, a análise de Características do Comportamento Empreendedor (CCEs) de dois importantes presidentes corresponsáveis pela construção da Administração Pública (State Building) Brasileira: Getúlio Vargas e Juscelino Kubitschek (JK). Esta proposta se justifica pela necessidade de renovação da administração pública do Brasil e da delimitação de características de um perfil empreendedor no contexto público brasileiro. Para sua operacionalização, utilizou-se da pesquisa documental. Em termos de resultados, esta pesquisa proporciona um olhar para a ação empreendedora e política que norteia a visão de dois importantes governantes para o Brasil. As características que nortearam o perfil empreendedor de GV e JK foram fundamentais para a construção do Estado Brasileiro, sobretudo no que concerne ao desenvolvimento do aparelho do Estado e de políticas públicas urbanas.

Palavras-chave: Empreendedorismo no Setor Público; Getúlio Vargas; Juscelino Kubitschek.

\section{ENTREPRENEURIAL BEHAVIOR IN THE PUBLIC SECTOR: A COMPARATIVE ANALYSIS OF TWO PRESIDENTS OF BRAZIL}

\begin{abstract}
This paper analysis Features of Entrepreneurial Behavior (FEBs) of two important presidents share responsibility for construction of Brazilian Public Administration (State Building): Getulio Vargas and Juscelino Kubitschek (JK). This proposal is justified by the need for renewal of public administration in Brazil and defining characteristics of an entrepreneurial profile in the public context in Brazil. For its operationalization has used the documentary research. In terms of results, this

\footnotetext{
1 Endereço: Rua Afonso Pena, 105, Lavras - MG. E-mail: isabellamonteiro_93@hotmail.com

2 E-mail: denisrenatodeoliveira@gmail.com

${ }^{3}$ E-mail: adm_josiel@yahoo.com.br

${ }^{4}$ E-mail: magnus@ufv.br
}

MONTEIRO, I.; OLIVEIRA, D.; VALADARES, J. L.; EMMENDOERFER, M. Comportamento empreendedor no setor público: análise comparada de dois presidentes no Brasil. Revista de Empreendedorismo e Gestão de Pequenas Empresas, v.5, n.2, 2016. 
research provides a look at the entrepreneurial and political action that guides the two important rulers' vision for Brazil. The characteristics that guided the entrepreneurial profile of GV and JK were fundamental for the construction of the Brazilian State, particularly regarding the development of the state apparatus and urban public policies.

Keywords: Entrepreneurship in the Public Sector; Getúlio Vargas; Juscelino Kubitschek.

\section{Introdução}

No horizonte de transformações da administração pública brasileira ocorridas nas últimas décadas, emergiu a necessidade das organizações públicas em ajustarem-se a uma nova realidade de demandas sociais, especialmente após o período de redemocratização do Estado Brasileiro (DA COSTA, 2008). Essas transformações destacaram-se mais concretamente a partir da década de 1930, com a criação do Departamento Administrativo do Serviço Público (DASP).

Nesse contexto de discussão, surge o debate sobre efetividade do gasto público. Nele defende-se uma alocação melhor de recursos, alcance de objetivos das políticas lastreados nos valores éticos e morais presentes no escopo da administração pública, melhoria da qualidade dos serviços e inclusão.

Observa-se que coube ao funcionalismo público os maiores impactos no que concerne às mudanças quanto à prestação de serviços à sociedade, ou seja, a nova forma de enxergar a administração pública recaiu sobre o servidor público, muitas vezes, desqualificado e despreparado para as novas demandas sociais. No entanto, essas mudanças trouxeram para o contexto da administração pública a preocupação com a formação de gestores públicos em termos de capacitação profissional em gestão, movimento caro ao Campo de Públicas no Brasil (PIRES et al., 2014).

Concomitantemente, intensifica-se o debate sobre a apropriação de práticas comuns no setor privado (uso da tecnologia, certificações de qualidade, práticas de gestão) para uma administração pública mais eficiente e flexível. Dentre essas práticas, destaca-se a apropriação do empreendedorismo como forma de tornar o 
aparelho estatal mais profissional e capaz de trazer respostas ágeis para as demandas sociais (OSBORNE; GAEBLER, 1994).

Os estudos e a prática do comportamento empreendedor têm atraído o interesse de pesquisadores da área pública o que, segundo Klein et al. (2010), pode revelar uma mudança na administração pública em termos estratégicos, em que a base da discussão é lastreada por aspectos inerentes ao uso de tecnologias informacionais, da consolidação das parcerias público-privadas, da busca pela accountability e pela necessidade de atendimento ao cidadão frente às suas novas demandas. Segundo os autores, há necessidade de os governos incluírem em suas agendas, uma formação empreendedora, pois o contexto recente é de privatização, da contratação e terceirização de serviços que tradicionalmente são funções do governo, como a construção de estradas, o funcionamento dos sistemas de informações, a construção e operação de sistemas prisionais. A perda de crédito das organizações públicas frente à sociedade evidencia que o empreendedorismo e a inovação evoca a ideia sobre o desenvolvimento de instituições públicas atualizadas e correspondentes aos interesses públicos.

Morais et al. (2015) revelam que as primeiras evidências do Empreendedorismo no Setor Público (ESP) remontam à segunda metade do século $\mathrm{XX}$, quando os governantes e gestores públicos passaram a internalizar conceitos e comportamentos até então desconhecidos ou não incorporados na Administração Pública. Assim, nas décadas de 60, 70 e 80 , os primeiros estudos sobre ESP evidenciaram-no como algo internalizado e manifestado, de forma concentrada no nível macro organizacional, na Administração Pública por meio do político, governante ou o principal gestor público da nação.

Deste modo, a ação empreendedora torna-se elemento central para o desenvolvimento das organizações públicas. Sobretudo no contexto do gerencialismo, o agir empreendedor torna-se elemento de distinção entre os gestores públicos. Características comportamentais como pró-atividade, alerta para oportunidades, capacidade de tomar riscos e inovação passam a ser bem quistas no perfil de gestores públicos.

As características do comportamento empreendedor também passam a serem bem quistas não somente no âmbito de gestão, mas também no âmbito 
político. Nesse sentido, ao apresentar um comportamento empreendedor, o ator político passa a constar com um rol de qualidades que intensificam sua capacidade de aglutinar os fluxos de soluções para os problemas sociais incorridos em determinado território. Por tais razões, torna-se essencial compreender a ação de atores políticos frente às necessidades sociais, pois neste ator reside uma maior capacidade de articular os interesses presentes na arena política (JONES, 1978; ZERBINATI; SOUTARIS, 2007; LEYDEN; LINK, 2015).

Diante desse posicionamento inicial, o presente trabalho insere-se neste debate, ou seja, procura compreender como as características do comportamento de determinados atores políticos podem interferir no processo de construção de políticas públicas de desenvolvimento nacional. Em outras palavras, busca-se promover uma reflexão sobre as implicações das características empreendedoras frente aos novos desafios, limites e possibilidades que são observados no contexto da gestão pública contemporânea.

Propõe-se, neste artigo, a análise de Características do Comportamento Empreendedor (CCEs) de dois importantes presidentes corresponsáveis pela construção da Administração Pública (State Building) Brasileira: Getúlio Vargas e Juscelino Kubitschek (JK). Essa proposta se justifica pela necessidade de renovação da administração pública no Brasil e da delimitação de características de um perfil empreendedor na administração pública no país. Desta forma, almeja-se refletir sobre a potencial aplicabilidade de características do comportamento empreendedor na administração pública brasileira.

Para sua operacionalização, este artigo, além desta introdução, é composto de mais cinco partes. Na primeira, são realizadas considerações a respeito da construção etimológica e conceitual do empreendedorismo. $\mathrm{Na}$ segunda, evidenciam-se as características do comportamento empreendedor. Na terceira, são colocados em termo os procedimentos metodológicos utilizados nesta pesquisa. $\mathrm{Na}$ quarta, expõem-se os resultados da pesquisa e por fim, na quinta seção são realizadas as conclusões deste estudo. 


\section{Discussões Etimológicas e Conceituais sobre Empreendedorismo}

A origem dos termos empreendedorismo, empreendedor e empreender vêm da palavra francesa entrepreneur, originada do latim (BOAVA; MACÊDO, 2009). Existe uma concordância na literatura de que o termo entrepreneur foi introduzido no contexto dos negócios por dois autores. O primeiro, Richard Cantillón (1755), era um bancário de família estimada cuja capacidade analítica para julgar situações lucrativas se destacava (THORTON, 2006). O segundo autor foi Jean-Baptiste Say (1880), o qual atuou como banqueiro, corretor de imóveis, jornalista, diretor, empresário e por fim, dedicou-se exclusivamente à academia (HART, 2001).

O empreendedor foi diferenciado do fornecedor de capital (entendido como investidor de risco da atualidade), sendo a principal causa para essa diferenciação da industrialização. Na metade do século XX a ideia de empreender surge como uma forma de inovar, isto é, o indivíduo, que além da capacidade de criar e de conceitualizar, tem a capacidade de inovar. "O termo empreendedorismo aponta para a execução de planos ou impulsos para a realização de um negócio ou para a introdução de uma nova inovação de gestão numa organização já estruturada" (CAMARGO; FARAH, 2010, p. 22).

O empreendedorismo pode ser compreendido como um fenômeno polissêmico, de modo que possui uma variedade de sentidos e abrange diversas áreas do conhecimento. Para Low (2001), o conceito é amplo se consideradas as possibilidades de analisá-lo a partir de diferentes disciplinas. No entanto, somente nos últimos dois séculos passou a ser estudado com austeridade, tornando-se objeto de interesse científico significativo (FALCONE; OSBORNE, 2005).

Com o desenvolvimento do contexto histórico capitalista (COSTA et al., 2011), o empreendedorismo ganhou força sobretudo no discurso acerca do desenvolvimento em países de centros. Além disso, surgiram vários conceitos e definições sob vários ângulos (economia, sociologia, psicologia, filosofia), assegurando em sua mais profunda base um caráter transdisciplinar e multidisciplinar (BOAVA; MACEDO, 2007). 
Filion (1999) interpreta essa figura como alguém que imagina, aprimora e realiza suas ideias e visões. Portanto, o empreendedorismo pode ser considerado um fenômeno social que traz consigo implicações de diversas naturezas, sejam psicológicas, sociais, culturais ou econômicas.

Com base nesse argumento, é possível observar ações empreendedoras desde a época primitiva, da evolução humana, pois para sobreviver, o homem precisava inovar na construção de diversas ferramentas a fim de agilizar a caça de animais. No entanto, o empreendedorismo ganha força no contexto histórico no final do século $X I X$ e início do século $X X$, com a ascensão do modelo capitalista de produção e com a Revolução Industrial. Naquela época, os empreendedores passaram a ser confundidos com os gerentes ou administradores, sendo considerados como aqueles que organizam, planejam, dirigem e controlam as ações desenvolvidas dentro da organização (DORNELAS, 2005).

Segundo Filion (1997), dentre as possibilidades de estudos sobre empreendedorismo, duas vertentes ganham maior destaque: a vertente econômica, representada por pensadores como Schumpeter (1997); e a comportamental, representada por pensadores como McClelland (1972). A corrente econômica caracteriza o empreendedor como inovador e busca identificar a função dele. Já a corrente comportamentalista tem por objetivo compreender a figura pessoal do empreendedor, bem como suas características, hábitos e atitudes.

Dentre as contribuições dos economistas, Joseph Schumpeter se destaca pela sua abordagem, a chamada Schumpeteriana. Segundo Gimenez, Ferreira e Ramos (2008), Schumpeter entende o empreendedorismo como uma função econômica, cujo foco é a inovação e o centro do termo está no ajuste e manutenção do equilíbrio.

Outras três abordagens são destacadas no contexto da economia: a que tem como fim a distribuição de recursos, a que enfatiza os processos de mercado e a que aborda a relação entre o empreendedor e a firma (CASSON, 1990). Nesse contexto, Marshall (1982) afirma que os empreendedores possuem habilidades em comum, mas diferenciam-se no que tange ao sucesso de seu empreendimento, visto que esse fator depende do meio econômico. 
A abordagem comportamental, por outro lado, considera que o principal instrumento do desenvolvimento social e econômico é o conjunto de valor onde o empreendedor é o protagonista que busca por sua realização pessoal. David McClelland desenvolveu estudos focados no comportamento empreendedor e tinha como objetivo principal desenvolver pesquisas que explicassem as razões que levavam indivíduos específicos a se envolverem com empreendimentos (GIMENEZ; FERREIRA; RAMOS, 2008).

Na concepção de McClelland (1972) surge a noção de papel, no sentido que o comportamento empreendedor é um entre diferentes papéis que o indivíduo assume na vida social. Este se vincula à intensidade de uma força central no comportamento empreendedor que ele denominou como necessidade de realização. No centro deste papel estão as características que compõem o comportamento empreendedor (GIMENEZ; FERREIRA; RAMOS, 2008).

De acordo com os estudos realizados por McClelland (1972), os indivíduos podem ser motivados por três tipos de necessidades: a) a de realização pessoal; b) a de planejamento e c) a de poder. Nesse bojo, McClelland (1972) aponta que um indivíduo com alta necessidade de realização está mais atento às estruturas sociais e oportunidades, já que possui vistas a alcançar o sucesso profissional. Conforme o autor, a necessidade de realização leva os indivíduos a se interessarem por atividades construtivas que o levariam ao descobrimento de novos processos e produtos, caracterizados pelas inovações.

O Quadro 1 a seguir expõe uma articulação entre as três necessidades apontadas por McClelland (1972) para o empreendedor, juntamente com as dez características do empreendedor catalogadas pelo UNCTAD (2008) como categorias centrais para a compreensão do comportamento empreendedor. 
QUADRO 1 - CARACTERÍSTICAS DO COMPORTAMENTO EMPREENDEDOR (CCES). CATEGORIA A: REALIZAÇÃO

CCE A1: Busca de oportunidades e iniciativa

Faz as coisas antes de solicitado, ou antes de ser forçado pelas circunstâncias; Age para expandir o negócio a novas áreas, produtos ou serviços; Aproveita oportunidades fora do comum para começar um negócio, obter financiamentos, equipamentos, terrenos, local de trabalho ou assistência.

\section{CCE A2: Correr riscos calculados}

Avalia alternativa e calcula riscos deliberadamente; Age para reduzir os riscos ou controlar os resultados; Coloca-se em situações que implicam desafios ou riscos moderados.

\section{CCE A3: Persistência}

Age diante de um obstáculo significativo; Age repetidamente ou muda de estratégia, a fim de enfrentar um desafio ou superar um obstáculo; Faz um sacrifício pessoal ou desenvolve um esforço extraordinário para completar uma tarefa.

CCE A4: Exigência de qualidade e eficiência

Encontra maneiras de fazer as coisas da melhor forma, mais rápido ou mais barato; Age de maneira a fazer coisas que satisfazem ou excedem padrões de excelência; Desenvolve ou utiliza procedimentos para assegurar que o trabalho seja terminado a tempo ou que o trabalho atenda a padrões de qualidade previamente combinados.

\section{CCE A5: Comprometimento}

Assume responsabilidade pessoal pelo desempenho necessário ao atingimento de metas e objetivos; colabora com os empregados ou se coloca no lugar deles, se necessário, para terminar um trabalho; esmera-se em manter os clientes satisfeitos e coloca em primeiro lugar a boa vontade a longo prazo, acima do lucro a curto prazo.

\section{CATEGORIA B: PLANEJAMENTO}

CCE B1: Busca de informações - Dedica-se pessoalmente a obter informações de clientes, fornecedores e concorrentes; Investiga pessoalmente como fabricar um produto ou fornecer um serviço; Consulta especialista para obter assessoria técnica ou comercial.

CCE B2: Estabelecimento de metas - Estabelece metas e objetivos que são desafiantes e que têm significado pessoal; define metas de longo prazo, claras e específicas; Estabelece objetivos mensuráveis e de curto prazo.

CCE B3: Planejamento e monitoramento sistemáticos - Planeja dividindo tarefas de grande porte em subtarefas com prazos definidos; Constantemente revisa seus planos, levando em conta os resultados obtidos e mudanças circunstanciais; Mantém registros financeiros e utiliza-os para tomar decisões.

\section{CATEGORIA C: PODER}

CCE C1: Persuasão e redes de contato - Utiliza estratégias deliberadas para influenciar ou persuadir os outros; Utiliza pessoas chave como agentes para atingir seus próprios objetivos; Age para desenvolver e manter relações comerciais.

CCE C2: Independência e autoconfiança - Busca autonomia em relação a normas e controles de outros; Mantém seu ponto de vista mesmo diante da oposição ou de resultados inicialmente desanimadores; Expressa confiança na sua própria capacidade de completar uma tarefa difícil ou de enfrentar um desafio.

FONTE: Adaptado de UNCTAD (2008).

A partir da articulação entre as diversas características enumeradas no Quadro 1, os empreendedores poderiam alcançar o sucesso e a busca por novas oportunidades dentro ou fora das organizações. Segundo o pensamento dos comportamentalistas, a partir desta gama de características, consideradas próprias do comportamento empreendedor, as pessoas poderiam contribuir para uma cultura onde as mudanças seriam tomadas de uma maneira receptiva. $O$ risco não seria um MONTEIRO, I.; OLIVEIRA, D.; VALADARES, J. L.; EMMENDOERFER, M. Comportamento empreendedor no setor público: análise comparada de dois presidentes no Brasil. Revista de Empreendedorismo e Gestão de Pequenas Empresas, v.5, n.2, 2016. 
elemento de inibição do comportamento dos empresários e a inovação seria a base de todo processo (VALADARES; EMMENDOERFER, 2015).

Nesse discurso, o que está por trás do sucesso de uma organização é um indivíduo com as devidas características e disposição suficiente para administrá-la e levá-la ao sucesso. Conforme Pereira e Santos (1995), o empreendedor bemsucedido passa a ser interpretado como uma pessoa que possui características encontradas em qualquer pessoa. O que o diferencia é o grau de intensidade de uma para outra característica. Sua personalidade e seus talentos conduzem-no para o sucesso, conseguindo a concretização dos seus sonhos e objetivos.

Cabe considerar o teor ideológico nesse discurso. De fato, é possível observar certo heroísmo dado ao empreendedor (comumente a ordem do discurso do herói). A construção desse discurso sobre o empreendedor pode ser vista em trabalho como de Costa et al., (2011) de forma mais aprofundada. No entanto, apesar de assumir e compreender a existência de contradições da "ideologia do empreendedorismo", entende-se que há conceitos importantes para o profissional do campo de públicas, no que tange a valores e desafios que são impostos aos atuais servidores públicos.

\section{Procedimentos Metodológicos}

Quanto à abordagem, esta pesquisa se caracteriza, predominatemente, como qualitativa, uma vez que a natureza do objeto em estudo demanda uma investigação com inspiração biográfica para analisar comportamentos empreendedores de pessoas notáveis que já faleceram e marcaram a construção de uma nação em um determinado momento da história. Nesse sentido, as "unidades de análise" são duas pessoas que foram presidentes do Brasil: Getúlio Vargas e Juscelino Kubitschek (JK).

Assim, para analisar os comportamentos empreendedores dessas duas pessaos, os métodos escolhidos para o seu desenvolvimento foram o documental e o bibliográfico (NEVES, 1996; GIL, 2002). A lista de documentos analisados pode ser vista no Quadro 2. 
QUADRO 2 - LISTA DE DOCUMENTOS ANALISADOS.

\begin{tabular}{|c|c|c|}
\hline DOCUMENTOS & TIPO & ANO \\
\hline JK: o artista do impossível. & Livro & 2001 \\
\hline JK: como nasce uma estrela. & Livro & 2002 \\
\hline $\begin{array}{c}\text { "O Brasil não é só uma doença": o } \\
\text { programa de saúde pública de Juscelino } \\
\text { Kubitschek. }\end{array}$ & Artigo & 2009 \\
\hline $\begin{array}{c}\text { Getúlio: Dos anos de formação à } \\
\text { conquista do poder (1882-1930). }\end{array}$ & Livro \\
\hline $\begin{array}{c}\text { A Era Vargas: desenvolvimento, } \\
\text { economia e sociedade. }\end{array}$ & Artigo & 2012 \\
\hline $\begin{array}{c}\text { Getúlio: Do governo provisório à ditadura } \\
\text { do Estado Novo (1930-1945). }\end{array}$ & Livro \\
\hline $\begin{array}{c}\text { Getúlio: Da volta pela consagração } \\
\text { popular ao suicídio (1945-1954). }\end{array}$ & Livro & 2013 \\
\hline
\end{tabular}

FONTE: Elaborado pelos autores (2016)

Após a coleta de dados, utilizou-se a análise de conteúdo. Segundo Bardin (2006), a análise de conteúdo visa identificar o que está sendo mencionado a respeito de determinado tema e trata-se de uma interpretação pessoal por parte do pesquisador com relação à percepção que se tem dos dados. A análise de conteúdo é de extrema importância para estudos relacionados à motivação, crenças, valores e tendências. Desta forma, as categorias de análise foram as Características do Comportamento Empreendedor (CCEs), indicadas no Quadro 1 da seção anterior, que após o cotejo de dados à luz da teorização sobre empreendedorismo apresentada, permitiu organizar e apresentar os resultados a seguir.

\section{CCEs de Getúlio Vargas}

Getúlio Dornelles Vargas nasceu em 19 de abril de 1882, no município de São Borja, situado no estado do Rio Grande do Sul. Era o terceiro de cinco filhos do casal Manuel do Nascimento Vargas e Cândida Dornelles Vargas, tradicional família de fazendeiros da região. Formou-se em direito em 1907 e em 1909, elegeu-se Deputado Estadual no Rio Grande do Sul, reeleito por mais dois mandatos. Em seguida, foi eleito governador do estado do Rio Grande do Sul e diante de um golpe que depôs o atual presidente da república naquela época, Washington Luís, Getúlio Vargas foi eleito chefe do Governo Provisório (1930-1934). Posteriormente foi eleito 
presidente do Governo Constitucionalista (1934-1937) e ditador do Estado Novo (1937-1945) (NETO, 2013).

Getúlio Vargas foi uma figura de suma relevância para a construção da burocracia no Brasil, sobretudo no que concerne a implementação de diversos programas e políticas para a profissionalização e 0 desenvolvimento da administração pública no Brasil. No Quadro 3, são apresentadas as principais realizações de Vargas durante os dezenove anos em que esteve no poder.

QUADRO 3 - AÇÕES DO GOVERNO GETÚLIO VARGAS.

\begin{tabular}{|c|c|}
\hline \multicolumn{2}{|c|}{ GOVERNO PROVISÓRIO (1930 - 1934) } \\
\hline DATA & REALIZAÇÓES \\
\hline 1930 & $\begin{array}{l}\text { - Instaura uma ditadura no país e inicia políticas de modernização na agricultura, na } \\
\text { indústria e na economia; e } \\
\text { - Institui o Conselho Nacional do Café e o Instituto do Cacau e cria nesse mesmo ano o } \\
\text { Ministério do Trabalho e Emprego (MTE), o Ministério da Indústria, do Comércio, da } \\
\text { Educação (MEC) e o Ministério da Saúde (MS). }\end{array}$ \\
\hline 1931 & - Derruba a Constituição Brasileira causando a indignação dos opositores. \\
\hline 1932 & $\begin{array}{l}\text { - Enfrenta uma revolta arquitetada pela oposição com o objetivo de criar uma nova } \\
\text { constituição para o país e que conta com o apoio de diversos estados: Minas Gerais, } \\
\text { Rio de Janeiro e Rio Grande do Sul. }\end{array}$ \\
\hline \multicolumn{2}{|r|}{ GOVERNO CONSTITUCIONALISTA (1934 - 1937) } \\
\hline 1934 & - Aprova a "Nova Constituição Brasileira". \\
\hline 1935 & $\begin{array}{l}\text { - Instituiu a Lei de Segurança Nacional, que visava garantir a segurança do Estado } \\
\text { contra a subversão da lei e da ordem. }\end{array}$ \\
\hline 1936 & $\begin{array}{l}\text { - Sanciona a lei que subordina as polícias militares dos estados ao Exército Brasileiro e } \\
\text { inicia a ditadura do Estado Novo. }\end{array}$ \\
\hline \multicolumn{2}{|r|}{ ESTADO NOVO (1937 - 1945) } \\
\hline 1937 & $\begin{array}{l}\text { - Ordena o fechamento do Congresso Nacional, extinguindo os partidos políticos e } \\
\text { suspendendo a campanha presidencial e a Constituição Brasileira. }\end{array}$ \\
\hline 1938 & $\begin{array}{l}\text { - Instaura o Departamento Administrativo do Serviço Público (DASP) para controlar e } \\
\text { coordenar os órgãos públicos, e ainda, cria o Instituto Brasileiro de Geografia e } \\
\text { Estatística (IBGE). }\end{array}$ \\
\hline 1939 & $\begin{array}{l}\text { - Cria o Conselho Nacional do Petróleo (CLP); o Conselho de Águas e Energia Elétrica } \\
\text { (CNAEE) e o Departamento de Imprensa e Propaganda (DIP), que tinha por objetivo } \\
\text { fazer propaganda dos atos do governo; } \\
\text { - Censura jornais, rádios, cinema e outros órgãos de imprensa; e } \\
\text { - Inicia uma repressão política marcada pela perseguição, prisão e até tortura de } \\
\text { opositores do seu governo. }\end{array}$ \\
\hline 1941 & - Funda a Companhia Siderúrgica Nacional (CSN). \\
\hline 1942 & $\begin{array}{l}\text { - Cria a Consolidação das Leis do Trabalho (CLT), instituindo o salário mínimo ao } \\
\text { trabalhador e garantindo direitos como a emissão da carteira profissional, jornada de } \\
48 \text { horas semanais, férias anuais remuneradas, segurança e medicina do trabalho; } \\
\text { - Estabelece diretrizes para proteção do trabalho da mulher e do menor, previdência } \\
\text { social e regulamentações de sindicatos das classes trabalhadoras, ações que o } \\
\text { apelidam de "Pai dos pobres"; } \\
\text { - Cria a Companhia Vale do Rio Doce (CVRD); } \\
\text { - Inicia a transição do regime autoritário para o regime democrático, e marca novas } \\
\text { - eleições presidenciais ao se sentir pressionado pela oposição; } \\
\text { - Introduz a campanha de popularização de sua figura nos meios de comunicação com }\end{array}$ \\
\hline
\end{tabular}

MONTEIRO, I.; OLIVEIRA, D.; VALADARES, J. L.; EMMENDOERFER, M. Comportamento empreendedor no setor público: análise comparada de dois presidentes no Brasil. Revista de Empreendedorismo e Gestão de Pequenas Empresas, v.5, n.2, 2016. 
o objetivo de assegurar maior apoio das classes trabalhadoras; e

\begin{tabular}{|c|c|}
\hline & $\begin{array}{l}\text { o objetivo de assegurar maior apoio das classes trabalhadoras; e } \\
\text { - Estabelece estratégias para enfrentar a oposição, a fim de criar mecanismos de } \\
\text { transição seguros que fossem capazes de modificar o regime mas o mantê-lo no } \\
\text { poder. }\end{array}$ \\
\hline 1943 & $\begin{array}{l}\text { - Cria a Companhia Nacional de Álcalis com o objetivo de produzir barrilha e sal; e } \\
\text { - Estabelece o Conselho Nacional de Política Industrial e Comercial (CNPIC). }\end{array}$ \\
\hline 1945 & $\begin{array}{l}\text { - Funda a Companhia Hidroelétrica do São Francisco (CHESF); } \\
\text { - Normaliza a atividade política e permite a fundação de partidos políticos - União } \\
\text { Democrática Nacional (UDN), o Partido Social Democrático (PSD) e o Partido } \\
\text { Trabalhista Brasileiro (PTB); } \\
\text { - É apoiado por movimentos que pedem sua permanência no poder; e } \\
\text { - É alvo de um golpe e as Forças Armadas, que o obrigam a renunciar à presidência. }\end{array}$ \\
\hline 1950 & $\begin{array}{l}\text { Decide candidatar-se, pelo Partido Trabalhista Brasileiro (PTB), às eleições } \\
\text { presidenciais, sendo eleito com quase quatro milhões de votos. }\end{array}$ \\
\hline 1951 & $\begin{array}{l}\text { - Amplia suas alianças políticas e se alia aos defensores do nacionalismo e do } \\
\text { liberalismo, que tinham opiniões divergentes acerca do futuro do país. }\end{array}$ \\
\hline 1952 & $\begin{array}{l}\text { - Continua o processo de industrialização e modernização do Brasil a fim de satisfazer } \\
\text { todas as classes e cria o Banco Nacional de Desenvolvimento Econômico e Social } \\
\text { (BNDE), atual BNDES, com o objetivo de financiar a longo prazo investimentos em } \\
\text { todos os segmentos da economia. }\end{array}$ \\
\hline 1953 & - Cria a Petrobrás e a Eletrobrás, duas grandes empresas estatais do setor energético. \\
\hline 1954 & $\begin{array}{l}\text { - Convoca João Goulart para assumir o Ministério do Trabalho; } \\
\text { - É criticado por promover a "esquerdização" do Brasil e praticar corrupção política, fato } \\
\text { que serviu de pretexto para que os grupos opositores iniciassem uma pressão política } \\
\text { a seu governo e exigissem sua renuncia à presidência; e } \\
\text { - Atenta contra a própria vida disparando um tiro contra o coração e deixando consigo } \\
\text { apenas uma carta-testamento na manhã de } 24 \text { de agosto de } 1954 \text {. }\end{array}$ \\
\hline
\end{tabular}
FONTE: Elaborado pelos autores com base em Neto $(2012,2013,2014)$.

A "Era Vargas" abrange um conjunto de políticas públicas que teve por objetivo alcançar certa autonomia política e econômica por meio de um desenvolvimento nacional independente, baseado em um Estado forte, centralizado e planejador. Vargas foi um homem que sintetizou o processo da complexa transição da República Velha para o moderno Estado Brasileiro, tornando-se o principal construtor da modernização do país e líder do desenvolvimento econômico e social (SAVIANI FILHO, 2013).

Conforme as características comportamentais empreendedoras (CCEs) apresentadas acima, é possível identificar em Getúlio Vargas a CCE A1 (Busca de oportunidades e iniciativa), visto que o ex-presidente buscou e aproveitou oportunidades para desenvolver e modernizar o país, salientando que agir é imprescindível para fazer os resultados aparecerem. É possível ainda visualizar em Vargas a CCE A2 (Correr riscos calculados), já que parte de suas ações foram no sentido de controlar os resultados, avaliar as possibilidades e coordenar suas MONTEIRO, I.; OLIVEIRA, D.; VALADARES, J. L.; EMMENDOERFER, M. Comportamento empreendedor no setor público: análise comparada de dois presidentes no Brasil. Revista de Empreendedorismo e Gestão de Pequenas Empresas, v.5, n.2, 2016. 
manobras políticas. Encontra-se em Getúlio, também, a CCE A3 (Persistência), quando se visualiza a disposição com que enfrentou a oposição ferrenha a seu governo e confrontou rebeliões e grupos formados.

Nota-se em GV, a CCE A4 (Eficiência), já que instituiu importantes Ministérios considerando a necessidade específica de cada área no país (inclui-se aqui a criação do DASP). Além disso, melhorou as condições de trabalho e de vida da classe trabalhadora, buscando atender e melhorar os padrões vigentes na época (inclui-se aqui a CLT). Encontra-se ainda no comportamento de GV, porém em menor grau, a CCE B3 (Planejamento), no que tange às suas campanhas e aspirações políticas para permanecer no poder. Além disso, a própria construção da Administração Pública Brasileira remete a esse valor.

GV foi um importante líder político que utilizava propaganda pessoal para influenciar a população e promover o seu governo. Além disso, utilizava com maestria a classe trabalhadora para atingir seus objetivos e ganhar apoio popular para permanecer no poder. Desse modo, a CCE C1 (Persuasão e Rede de Contatos) fez com que Vargas se mantivesse por tantos anos como presidente e líder político, visto que utilizou estratégias de governo e manteve relações políticas para alcançar suas metas.

Vargas era um político confiante, autoritário e independente, que mantinha seu ponto de vista mesmo diante da oposição, o que caracteriza a presença da CCE C2 (Independência e autoconfiança), pois expressava confiança e esbanjava simpatia para com a população, de modo que conquistou milhares de brasileiros, principalmente a classe trabalhadora.

\section{CCEs de Juscelino Kubitschek}

Juscelino Kubitschek de Oliveira nasceu em 12 de dezembro de 1902, no município de Diamantina, estado de Minas Gerais. De família humilde, era filho de João César de Oliveira (1872-1905), que trabalhava como caixeiro-viajante, e Júlia Kubitscheck (1873-1971), professora. O casal tinha outra filha que se chamava Maria da Conceição Kubitscheck de Oliveira, mais conhecida como "Naná". Desde 
criança, Juscelino mostrara ser uma pessoa estudiosa e interessada, almejando tornar-se médico. Desse modo, mudou-se para Belo Horizonte em 1920 e ingressou no curso de medicina na Universidade Federal de Minas Gerais (UFMG).

Após a formatura em 1927, Juscelino decidiu instalar seu próprio consultório e aos poucos, tornou-se um médico estimado e requisitado por todos (CONY, 2002). Durante a Revolução Constitucionalista de 1932, defendendo seu Estado como Capitão-Médico, JK conquistou a confiança do delegado federal Benedito Valadares Ribeiro. Após a revolução, o presidente Getúlio Vargas designou a Benedito Valadares o cargo de interventor de Minas Gerais e esse nomeou Juscelino como seu secretário de governo.

No mesmo ano, JK elegeu-se deputado federal, mas perdeu o mandato em 1937 com o surgimento do Estado Novo. Em seguida, foi surpreendido quando, em 1940, o governador Benedito Valadares o indicou novamente, desta vez para prefeito de Belo Horizonte. Após sua saída da prefeitura de Belo Horizonte, Juscelino elegeu-se Deputado Federal pelo Partido Social Democrático (PSD) nas eleições de 1945 e posteriormente foi eleito governador de Minas Gerais em janeiro de 1951, exercendo uma gestão eficiente e criando condições para se candidatar à Presidência da República. Após o suicídio de Getúlio Vargas, em 24 de agosto de 1954, o país estava estarrecido e passou a ser governado pelo vice-presidente João Café Filho. Porém, em 1955 houve a necessidade de uma nova campanha para presidência da República.

Em março de 1955, JK preparava-se para as eleições como candidato à Presidência da República. Durante sua campanha política, elaborou duas principais propostas para seu programa de governo, uma vez que pretendia colocar em prática: (1) a modernização, o desenvolvimento e o progresso; e (2) a intensificação do processo de industrialização do país. Considerado favorito, JK lançou sua candidatura através da aliança entre o Partido Social Democrático (PSD) e o Partido Trabalhista Brasileiro (PTB) e ainda contava com o apoio dos trabalhistas.

Eleito em três de outubro de 1955 por coalizão liderada pelo PSD, JK sofreu rebeliões e protestos da oposição contra a sua posse, exigindo uma mudança no quadro eleitoral que não previa a maioria absoluta para a eleição presidencial. Não obstante, foi necessária a deposição de Café Filho e Carlos Luz para que JK 
pudesse tomar posse em 31 de janeiro de 1956 para mandato de cinco anos.

Quadro 4 apresenta as suas principais realizações durante o período em que esteve no poder.

QUADRO 4 - AÇÕES DO GOVERNO DE JUSCELINO KUBITSCHEK.

\begin{tabular}{|c|c|}
\hline DATA & $\begin{array}{c}\text { RESIDÉNCIA DA REPÚBLICA (1956 - 1961) } \\
\text { REALIZAÇÓES }\end{array}$ \\
\hline 1956 & $\begin{array}{l}\text { - Cria o lema de governo: "50 anos em 5" e inicia uma política de governo cujo foco se } \\
\text { baseia no crescimento econômico, cujo objetivo é fazer da indústria o centro das } \\
\text { atividades nacionais; } \\
\text { - Instaura um projeto político e econômico que reforça o papel de um Estado planejador } \\
\text { - } \text { fomentador do desenvolvimento e da integração nacional; } \\
\text { - expoia seus principais auxiliares e distribui as tarefas que iriam competir a cada um, } \\
\text { - Inicia o "Plano de Metas", que prevê } 31 \text { metas distribuídas em seis grupos: } \\
\text { alimentação, educação, energia, indústria de base, transporte e a "meta síntese", } \\
\text { construção da nova capital federal em Brasília; e } \\
\text { - Inaugura a fábrica de caminhões da Mercedes-Benz (São Bernardo do Campo). }\end{array}$ \\
\hline 1957 & $\begin{array}{l}\text { - Inaugura, por meio da rodovia BR-3 (Rio-Belo Horizonte), os investimentos para } \\
\text { construção de um amplo sistema rodoviário no país; } \\
\text { - Lança a Superintendência do Desenvolvimento do Nordeste (SUDENE) cuja finalidade } \\
\text { - é promover o desenvolvimento da região Nordeste; } \\
\text { - Incentiva o crescimento da indústria siderúrgica, com investimentos para o aumento da } \\
\text { capacidade de produção de aço (2 para } 5 \text { milhões de toneladas em três anos); } \\
\text { Executa a meta de aumento da fabricação de caminhões, jipes, automóveis, tratores e } \\
\text { navios para escoamento da produção; } \\
\text { - Enfrenta a greve dos "400 mil" com pauta de reivindicações de salários para } \\
\text { compensar a inflação; e } \\
\text { - Enfrenta a reivindicação das "Ligas Camponesas" por reforma agrária no Nordeste. }\end{array}$ \\
\hline 1958 & $\begin{array}{l}\text { - Assiste a apresentação do primeiro automóvel de passageiros, fabricado em São } \\
\text { Paulo, que marca o fortalecimento da política de industrialização automobilística; } \\
\text { - Entrega as rodovias São Paulo-Cuiabá e Fernão Dias, que liga Belo Horizonte à São } \\
\text { Paulo; } \\
\text { - Exibe um estilo próprio de governo, que o caracteriza como "presidente voador", } \\
\text {-presidente bossa-nova" e "presidente sorriso"; e } \\
\text { Restabelece um clima de euforia e entusiasmo, cativando com seu estilo confiante e } \\
\text { simpático os brasileiros. }\end{array}$ \\
\hline 1959 & $\begin{array}{l}\text { - Obtém reconhecimento pelo desenvolvimento industrial e abertura econômica; } \\
\text { - Cria novas usinas e hidrelétricas (Furnas e Três Marias); } \\
\text { - } \text { Dá ênfase à indústria de produção cultural no Brasil, com a implantação do Cinema } \\
\text { - Gavante à àrização da Bossa Nova, do futebol e da televisão; e } \\
\text { salário mínimo e da oferta de empregos. }\end{array}$ \\
\hline 1960 & $\begin{array}{l}\text { - Inaugura Brasília, a nova capital do Brasil; } \\
\text { - Consolida as parcerias com grandes personalidades, como o urbanista Lucio Costa e o } \\
\text { arquiteto Oscar Niemeyer; e } \\
\text { - Descentraliza o poder e promove o desenvolvimento de outras regiões do país. }\end{array}$ \\
\hline 1961 & $\begin{array}{l}\text { econômica e pela oposição ao governo; e } \\
\text { flação" devido o crescimento acelerado da indústria e os gastos } \\
\text { va capital do país. }\end{array}$ \\
\hline 1961 & ia da república por Jânio Quadros. \\
\hline
\end{tabular}

MONTEIRO, I.; OLIVEIRA, D.; VALADARES, J. L.; EMMENDOERFER, M. Comportamento empreendedor no setor público: análise comparada de dois presidentes no Brasil. Revista de Empreendedorismo e Gestão de Pequenas Empresas, v.5, n.2, 2016. 
Durante o governo JK, o Brasil teve o maior salário mínimo da história trabalhista e o crescimento e desenvolvimento nacional teve a média de $7 \%$ em seu mandato. O programa de governo de JK possibilitou a expansão econômica e industrial, porém apresentou pontos negativos, já que colocou o país na dependência do capital externo e aumentou significativamente a inflação e a dívida pública. A pobreza e a violência nesse período também aumentaram consideravelmente em decorrência de problemas relacionados à migração descontrolada. Contudo, JK contribuiu de forma significativa para a transformação do Brasil, de modo que o país passou a ser visto como um cenário de possibilidades e oportunidades.

Conforme as CCEs pôde-se identificar em Juscelino Kubitscheck a presença de oito características empreendedoras, mas algumas com um maior grau de intensidade do que as outras, o que indica empreendeorismo (McCLELLAND, 1972). É possível identificar em JK a CCE A1 (Busca de oportunidades e iniciativa), já que o ex-presidente foi um visionário e aproveitou a estabilidade política existente no país para expandir novas áreas durante seu governo com a intenção de desenvolver a economia e modernizar o país. Durante o seu mandato, JK não foi forçado pelas circunstâncias, ou seja, não agiu sob pressão, o que beneficiou sua gestão, visto que pôde colocar suas ideias em prática e desenvolvê-las.

É notório a presença da CCE A3 (Persistência) em Juscelino, de modo que assumiu a responsabilidade de cumprir as tarefas para alcançar as metas previstas em seu plano de governo. Dessa forma, foi persistente e agiu de diferentes maneiras para finalizar suas obras, uma vez que um projeto bom e bem realizado deve principalmente ser concluído. Outra característica encontrada no ex-presidente é a CCE A4 (Exigência de qualidade), pois investiu e aperfeiçoou sempre na qualidade de suas ações, buscando parcerias e alianças com mestres que o ajudaram a desempenhar sua gestão como, por exemplo, o arquiteto Oscar Niemayer, considerado uma das figuras-chave no desenvolvimento da arquitetura moderna. Tal característica é de extrema importância nos dias atuais, de modo que não basta ser bom, é necessário sempre atualizar-se, inovando e preparando-se para melhorar a cada dia. 
Identifica-se também a CCE A5 (Comprometimento) no comportamento de Juscelino, de modo que assumia a responsabilidade pelos resultados obtidos durante seu governo e se empenhava para concluir alguma tarefa em andamento. Juscelino foi um empreendedor que estabelecia metas e objetivos específicos e desafiantes e se esmerava para manter o povo satisfeito com o seu governo. Desse modo, a CCE B2 (Estabelecimento de metas) levou o ex-presidente para a direção correta, visto que definiu em seu programa de governo metas de longo prazo a serem cumpridas.

Por meio da CCE B3 (Planejamento e monitoramento sistemáticos), Juscelino foi capaz de planejar seu programa de governo e dividir o Plano de Metas em seis grupos com prazos definidos a fim de atender aos setores necessitados. Dessa forma, o empreendedor que planeja suas ações tende a obter melhores resultados e assim atingir seus objetivos e metas.

Nota-se ainda em Juscelino, porém em menor grau, a CCE C1 (Persuasão e redes de contato), pois buscava consolidar parcerias e alianças com grandes personalidades para fortalecer sua gestão e diminuir os riscos de suas ações. Por fim, é possível identificar em JK a CCE C2 (Independência e autoconfiança), uma vez que utilizava de seu estilo confiante e carismático de governar para se promover politicamente e, consequentemente, cativar o povo.

\section{Análise Comparativa das CCEs de Getúlio Vargas e Juscelino Kubitschek}

Diante dos resultados obtidos, é possível identificar em Getúlio Vargas e em Juscelino Kubitschek a presença de características de comportamento empreendedor, mas que se diferem em alguns aspectos de acordo com as realizações de cada ex-gestor. Não se trata de tomar o perfil dos dois atores políticos analisados da mesma maneira que se toma o do empreendedor no contexto privado. Trata-se, de outra forma, de entender quais possíveis traços empreendedores são possíveis encontrar no perfil dos dois presidentes.

As características empreendedoras encontradas no perfil dos dois gestores contribuem para o entendimento de que é possível desenvolver um perfil no setor 
público que em sua essência permitem a proatividade, o alerta para oportunidades e também para inovação. Evidentemente que os significados dessas características tomarão conotações caras ao contexto do setor público. Por esse entendimento, as características empreendedoras passam a ser categorias fundamentais para a compreensão do perfil empreendedor de atores políticos.

O Quadro 5 a seguir apresenta um resumo das CCEs identificadas em Getúlio Vargas e Juscelino Kubitschek:

QUADRO 5 - CCES IDENTIFICADAS EM GETÚLIO VARGAS E JUSCELINO KUBITSCHEK.

\begin{tabular}{|c|c|}
\hline GETÚLIO VARGAS & JUSCELINO KUBITSCHEK \\
Necessidade de Realização & $\begin{array}{c}\text { Necessidade de Realização } \\
\text { Busca de oportunidades e iniciativa }\end{array}$ \\
\hline Correr riscos calculados & Persistência \\
\hline Persistência & Comprometimento \\
\hline Eficiência & Exigência de qualidade \\
\hline Necessidade de Planejamento & Necessidade de Planejamento \\
Planejamento* & Estabelecimento de metas \\
\hline Necessidade de Poder & Planejamento \\
\hline Persuasão e rede de contatos & Necessidade de Poder \\
\hline Independência e autoconfiança & Persuasão e redes de contatoto \\
\hline
\end{tabular}

FONTE: Elaborado pelos autores.

NOTA: * A característica de planejamento de Getúlio Vargas está relacionada apenas às suas campanhas e aspirações políticas para permanecer no poder.

${ }_{* *}^{*}$ A característica de persuasão e rede de contatos de Juscelino Kubitschek está relacionada apenas à consolidação de parcerias com grandes personalidades, como o urbanista Lucio Costa e o arquiteto Oscar Niemeyer.

${ }^{* * *}$ A característica de independência e autoconfiança de Juscelino Kubitschek está relacionada apenas ao seu estilo confiante e simpático de governar, de modo que se promovia politicamente.

Conforme os dados acima, é possível identificar características empreendedoras comuns em GV e JK, como: busca de oportunidades e iniciativa, persistência, planejamento, persuasão e rede de contatos, independência e autoconfiança. Tais características, de forma propedêutica, talvez possam ilustrar certa tendência ou ser o principal indício de que há a necessidade de os profissionais do campo de públicas perceberem que o desenvolvimento de características deste tipo pode representar uma tentativa para tornar o gestor público capaz de desenvolver atividades que desafiem a atual máquina pública.

Por meio da análise do comportamento empreendedor identificado em GV e JK é possível estimular os atuais gestores a implementarem uma política focada em diagnosticar estratégias e oportunidades de melhorias na gestão pública.

MONTEIRO, I.; OLIVEIRA, D.; VALADARES, J. L.; EMMENDOERFER, M. Comportamento empreendedor no setor público: análise comparada de dois presidentes no Brasil. Revista de Empreendedorismo e Gestão de Pequenas Empresas, v.5, n.2, 2016. 
Em GV destaca-se a presença de um comportamento empreendedor voltado para suprir suas necessidades de realização e poder, visto seu desejo político de controlar, decidir e influenciar outros indivíduos. Não obstante, percebe-se ainda uma forte necessidade de realização pessoal, principalmente pelo fato de suas ações sempre serem balizadas por suas aspirações e objetivos individuais.

Em contrapartida, JK destaca-se por possuir fortemente uma necessidade de realização e planejamento, notada pelo desejo individual em atingir objetivos e metas da melhor maneira, concluir suas ações pautando-se pela qualidade dos serviços. Além disso, sempre esteve disposto a assumir responsabilidades e desafios e estabelecia para si mesmo um objetivo que o motivasse a atingir.

Pode-se dizer que os "Anos Dourados" e a "Era Vargas" têm como principal ponto em comum, estratégias e políticas de desenvolvimento, respeitadas as condições e aspectos conjunturais de seu tempo. A economia no governo getulista apresentou medidas consideradas intervencionistas que buscavam diversificar a agricultura, estimular o desenvolvimento industrial no país, além de instaurar a modernização e o progresso em diversos setores. Já JK provocou um surto de desenvolvimento jamais visto, de modo que expandiu a economia e os setores de energia, transporte, saúde, indústria de base, além da construção de Brasília.

\section{Considerações Finais}

A análise realizada nesta pesquisa é pertinente com o atual quadro de renovação buscado no perfil de gestores e atores políticos nas organizações públicas no Brasil e no mundo. Como visto, após o período de reformas, que ocorreram sobretudo após os governos de Margareth Thatcher e Ronald Reagan nos anos 1970 e 1980, as organizações públicas passaram a buscar um comportamento mais flexível e proativo dos atores que agem por elas.

Nessa perspectiva, ao tomar figuras políticas importantes no âmbito de instituições políticas como dois presidentes, esta pesquisa proporciona um olhar para a ação empreendedora e política que norteia a visão de dois importantes governantes para o Brasil. É comum acordo que esta ação, tanto de GV como JK, foi 
fundamental para a construção do Estado Brasileiro, sobretudo no que concerne ao desenvolvimento do aparelho do estado e de políticas públicas urbanas.

Ao estabelecer este olhar para as características empreendedoras presentes nesses governantes, este trabalho contribui com uma lacuna nos estudos sobre empreendedorismo no setor público. Nesse sentido, observa-se que apesar de o assunto estar mais ligado ao contexto empresarial, é possível observar o comportamento empreendedor no setor público e tomar como fato a compreensão de que o empreendedorismo pode manifestar-se independentemente do local ou setor no qual está sendo desenvolvido. Em outras palavras, o empreendedorismo manifesta-se no contexto social, e como fenômeno é multifacetado e sem fronteiras (BOAVA; MACEDO, 2011). Para ser desenvolvido, basta ter uma visão de futuro que permita ao ator político planejar o presente.

Embora não se descarta, ao se analisar as CCEs de ex-gestores públicos brasileiros renomados, a existência de empreendedores natos, que nascem com algumas características ou traços essenciais ao sucesso pessoal e profissional, deve-se ressaltar também, que características empreendedoras podem ser desenvolvidas e influenciadas principalmente pelo meio e condições conjunturais, talvez mais diretamente relacionadas às situações de crise e instabilidade que levam à necessidade de mudança.

Em seus estudos, McClelland (1972) aponta que os indivíduos são motivados por três tipos de necessidades: realização pessoal, planejamento e poder. Essas necessidades permeiam dez características presentes no comportamento empreendedor.

Apesar de somente algumas CCEs terem sido identificadas em Getúlio Vargas e em Juscelino Kubitschek (o que talvez evidencie não ser necessário dominar todas elas, mas desenvolver um quadro específico de acordo com a necessidade e o contexto em que se está inserido), há uma aproximação interessante do comportamento empreendedor e da possibilidade de estabelecer uma cultura de mudanças no setor público.

Por serem presidentes e terem maior autonomia de liderança, este estudo revela que a capacidade de inovar e também de gerar mudanças no setor público tem relação direta com a legitimidade para tomar decisões. Isso implica na 
capacidade desse governante em articular suas bases político/partidárias e também os desejos, interesses sociais e empresariais envoltos na tomada de decisão de instituições políticas.

Como tais presidentes foram importantes líderes políticos e gestores públicos de sucesso, já que contribuíram de forma significativa para o desenvolvimento, inovação e modernização do Brasil e apresentaram características comuns, tem-se um indício de que as características empreendedoras presentes no comportamento dos gestores foram fundamentais para sustentar a visão política e de desenvolvimento. Implica dizer que o empreendedorismo político é essencial para a garantia de articulação dos fluxos de soluções para o território em questão. Nessa perspectiva, a ação de atores políticos carece tanto de habilidades técnicas, mas também políticas.

O empreendedorismo no setor público absorve uma categoria essencial: o poder, sobretudo o poder hierárquico weberiano e a capacidade de usar o cargo e o aparato estatal em seu favor. Tanto GV quanto JK souberam lidar bem com as problemáticas existentes nos seus governos por meio da persuasão e a utilização das redes de contato para que pudessem implementar a visão de futuro para o Brasil. Nesse sentido, dentre todas as outras categorias presentes no perfil desses atores políticos, a capacidade de articular seus planos por meio da influência, seja carismática ou até mesmo tradicional, foram cruciais.

Os resultados desta pesquisa também dão suporte para que o comportamento no setor público seja tomado por uma via alternativa daquela presente no senso comum de que o servidor público é apenas um cumpridor de tarefas. Em outras palavras, esta pesquisa dá suporte para entender que, conforme o nível de influência do cargo do ator político, esse é capaz de romper com a síndrome operacionalista presente na burocracia estatal de países como o Brasil e propor novas políticas e práticas para o alcance de novos patamares para o desenvolvimento do território.

Isso implica dizer que a categoria risco, tomada como característica do comportamento empreendedor, passa a ser significada não somente pela perspectiva econômica, mas também pela perspectiva social e política. 
Além disso, este estudo também dá suporte para o entendimento de que as ações de empreendedores públicos/políticos devem atuar sob um planejamento prévio com base em metas claras e que possam ser compartilhadas em equipe. Foi assim que tanto GV quanto JK conseguiram implementar suas visões, sobretudo, por absorver características bem presentes nas biografias de grandes empreendedores. Especificamente, puderam utilizar dessas características comportamentais para tornarem suas visões de construir o Estado Brasileiro efetivamente.

Diante disso, este estudo mostrou a importância e necessidade de se formar e capacitar os novos gestores púbicos para que sejam capazes de implementar ideias de renovação desse campo. Ainda que as contribuições desta pesquisa residem em um nível hierárquico mais estratégico, ou seja, em um nível de cúpula administrativa, não se pode menosprezar as contribuições da formação de um comportamento empreendedor na gestão pública atual. Manter esta discussão no âmbito do executivo permite levar as discussões e os resultados deste trabalho não só para o contexto da União, mas também para os estados e municípios no Brasil.

Pensar um comportamento empreendedor, principalmente no contexto dos municípios que ainda vigora um contexto de baixa qualificação de prefeitos e atores políticos importantes, como os secretários, é contribuir para o fortalecimento de uma gestão mais profissionalizada, em que os preceitos da transparência, eficiência e qualidade possam ser direcionadores da atuação do ator político. Apesar de não resolver todos os problemas sociais e econômicos, o comportamento empreendedor passa a ser o ativador de mudanças na gestão podendo gerar novas propostas e inclusive comportamentos e valores que busquem e visem a garantia do ethos republicano, que deve ser resguardado na gestão pública.

\section{Referências:}

BARDIN, L. Análise de conteúdo (L. de A. Rego \& A. Pinheiro, Trads.). Lisboa: Edições 70, 2006.

BOAVA, D. L. T; MACEDO, F. M. F. Constituição ontoteleológica do empreendedorismo. In: XXXI ENCONTRO DA ANPAD - EnANPAD, 2007, Rio de Janeiro. Anais... Rio de Janeiro, 2007. 
BOAVA, D. L. T.; MACEDO, F. M. F. Empreendedorismo explicitado à maneira dos filósofos. In: ENCONTRO DE ESTUDOS EM ESTRATÉGIA DA ASSOCIAÇÃO NACIONAL DE PESQUISA E PÓS GRADUAÇÃO EM ADMINISTRAÇÃO, 5., 2011, Porto Alegre. Anais... Porto Alegre: ANPAD, 2011. p. 1-18.

BOAVA, D. L. T.; MACEDO, F. M. F. Sentido axiológico do empreendedorismo. In: ENCONTRO DA ASSOCIAÇÃO NACIONAL DE PÓS-GRADUAÇÃO E PESQUISA EM ADMINISTRAÇÃO - EnANPAD, 33., 2009, São Paulo. Anais... São Paulo, 2009.

CAMARGO, S. H. C. R. V.; FARAH, O. E. Gestão empreendedora e intraempreendedora: estudos de casos brasileiros. Ribeirão Preto: Villimpress, 2010.

CASSON, M. Entrepreneurship. Aldershot: Edward Elgar, 1990.

CONY, C. H. JK: como nasce uma estrela. 2. ed. São Paulo : Record, 2002.

COSTA, A. M. da; BARROS, D. F.; CARVALHO, J. L. F. A dimensão histórica dos discursos acerca do empreendedor e do empreendedorismo. Revista de Administração Contemporânea, v. 15, n. 2, p. 179-197, 2011.

DA COSTA, F. L. Brasil: 200 anos de Estado; 200 anos de administração pública; 200 anos de reformas. Revista de Administração Pública, v. 42, n. 5, p. 829-874, 2008.

DORNELAS, J. C. A. Empreendedorismo: transformando ideias em negócios. 2. ed. Rio de Janeiro: Elsevier, 2005.

FALCONE, T.; OSBORNE S. Entrepreneurship: a diverse concept in a diverse world. Anais: Ibero Academy: Academy of Management. Faculdade de Economia Universidade Nova de Lisboa. Lisbon, Portugal - December, 8-11, 2005.

FILION, L. J. Empreendedores e Proprietários de Pequenos Negócios. Revista da Administração da Universidade de São Paulo, v. 34, n. 2, 1999.

FILION, L. J. From Entrepreneurship to Entreprenology. In: USASBE ANNUAL NATIONAL CONFERENCE, 1997, California. Proceedings... Winsconsin: Usasbe, 1997.

GIL, A. C. Como elaborar projetos de pesquisa. 4. ed. São Paulo: Atlas, 2002.

GIMENEZ, F. A. P.; FERREIRA, J. M.; RAMOS, S. C. Configuração empreendedora ou configurações empreendedoras? Indo um pouco além de mintzberg. In: ENCONTRO ANUAL DA ASSOCIAÇÃO DE PESQUISA E PÓS-GRADUAÇÃO EM ADMINISTRAÇÃO - EnANPAD, 32, 2008, Rio de Janeiro. Anais...Rio de Janeiro: ANPAD, 2008.

MONTEIRO, I.; OLIVEIRA, D.; VALADARES, J. L.; EMMENDOERFER, M. Comportamento empreendedor no setor público: análise comparada de dois presidentes no Brasil. Revista de Empreendedorismo e Gestão de Pequenas Empresas, v.5, n.2, 2016. 
HART, D. M. L. Life and works of Jean-Baptiste Say. 2001. Library of Economics and Liberty. Disponível em: <http://www.econlib.org/>.

JONES, P. The appeal of the political entrepreneur. British Journal of Political Science, v. 8, n. 4, p. 498-450, 1978.

KLEIN, P. G.; MAHONEY J. T.; MCGAHAN A. M.; PITELIS C. N. Toward a theory of public entrepreneurship. European Management Review, v. 7, n. 1, p. 1-15, 2010.

LEYDEN, D. P.; LINK, A. N. Public Sector Entrepreneurship: U.S. Technology and Innovation Policy. Oxford University Press, 2015.

LOW, M. B. The Adolescence of entrepreneurship research: specification of purpose. Entrepreneurship Theory and Practice, v. 25, n. 4, p. 17-25, 2001.

MARSHALL, A. Princípios de economia. São Paulo: Abril. 1982.

MCCLELLAND, D. Sociedade competitiva. Rio de Janeiro: Expressão e Cultura, 1972.

MORAIS, M. C. A.; VALADARES, J. L.; EMMENDOERFER, M. L.; TONELLI, D. Polissemias do empreendedorismo no setor público. Revista de Empreendedorismo e Gestão de Pequenas Empresas, v. 4, n. 1, p. 26-53, 2015.

MOREIRA, V. M. L. Os anos JK: industrialização e modelo oligárquico de desenvolvimento rural. In: FERREIRA, J.; DELGADO, L. de A. N. (org.). O Brasil republicano. O tempo da experiência democrática: Da democratização de 1945 ao golpe civil-militar de 1964. 1. ed. Rio de Janeiro: Civilização Brasileira, 2003, p.155194.

NETO, L. Getúlio: Da volta pela consagração popular ao suicídio (1945-1954). São Paulo: Companhia das Letras, 2014.

NETO, L. Getúlio: Do governo provisório à ditadura do Estado Novo (1930-1945). São Paulo: Companhia das Letras, 2013.

NETO, L. Getúlio: Dos anos de formação à conquista do poder (1882-1930). São Paulo: Companhia das Letras, 2012.

NEVES, J. L. Pesquisa qualitativa-características, usos e possibilidades. Caderno de Pesquisa em Administração, v. 1, n. 3, p. 103-113, 1996.

OSBORNE, D.; GAEBLER, T. Reinventando o governo: como o espírito empreendedor está transformando o setor público. Brasília: MH Comunicação, 1994.

PEREIRA, H. J.; SANTOS, S. A. Criando seu próprio negócio: como desenvolver o potencial empreendedor. Brasília: Sebrae, 1995.

MONTEIRO, I.; OLIVEIRA, D.; VALADARES, J. L.; EMMENDOERFER, M. Comportamento empreendedor no setor público: análise comparada de dois presidentes no Brasil. Revista de Empreendedorismo e Gestão de Pequenas Empresas, v.5, n.2, 2016. 
PIRES, V.; SILVA, S. A. M.; FONSECA, S. A.; VENDRAMINI, P.; COELHO, F. S. Dossiê - Campo de Públicas no Brasil: definição, movimento constitutivo e desafios atuais. Administração Pública e Gestão Social - APGS, v. 6, n. 3, p. 109-167, 2014.

SAVIANI FILHO, H. A Era Vargas: Desenvolvimento, Economia e Socidade. Economia e Sociedade (UNICAMP. Impresso), v. 22, n. 3, p. 855-860, 2013.

THORTON, M. Cantillón on the cause of the Business Cycle. The Quarterly Journal of Austrian Economics, v. 9, n. 3, 2006.

UNCTAD, UNITED NATIONS CONFERENCE ON TRADE AND DEVELOPMENT. Empretec. On-line. Disponível em: <http://www.unctad.org >. Acesso em jun. 2008.

VALADARES, J. L; EMMENDOERFER, M. L. A Incorporação do Empreendedorismo no Setor Público: reflexões baseadas no contexto brasileiro. Revista de Ciências da Administração - RCA, v. 17, n. 41, p. 82-98, 2015.

ZERBINATI, S.; SOUITARIS, V. Entrepreneurship in the public sector: a framework of analysis in European local governments. Entrepreneurship \& Regional Development: An International Journal, v. 17, n. 1, p. 43-64, 2007. 